\title{
ANTIBACTERIAL EFFECT OF OZONATED OLIVE OIL VERSUS SODIUM HYPOCHLORITE AGAINST ENTEROCOCCUS FAECALIS BACTERIA: IN VITRO STUDY
}

\author{
Nada Mohamed Wassef * and Marwa Aly Fouad *
}

\begin{abstract}
Background: The elimination of resistant bacterial strains such as Enterococcus faecalis present in infected canals is of paramount importance for successful root canal treatment. New alternative irrigants other than sodium hypochlorite have been proposed to achieve ideal endodontic treatment.
\end{abstract}

Aim: The aim of this study is to investigate antibacterial effect of ozonated olive oil versus sodium hypochlorite against Enterococcus faecalis bacteria.

Methodology: Agar well diffusion test was used to determine the antibacterial effect of ozonated olive oil and sodium hypochlorite against Enterococcus faecalis bacteria. The diameters of zones of bacterial inhibition formed around wells containing the test materials were measured and recorded after incubation for $24 \mathrm{~h}$ and $48 \mathrm{~h}$.

Results: The mean values of the diameter of the zones of bacterial inhibition were $13.28 \mathrm{~mm} \pm$ 1.127 and $21.22 \mathrm{~mm} \pm 1.396$ for sodium hypochlorite and ozonated olive oil respectively after 24 h. The results showed a statistically significant difference between the two groups. There was no change in the diameter of the bacterial inhibition zones after 48 hours.

Conclusions: The present study showed that antibacterial effect of ozonated oil is superior to that of sodium hypochlorite.

KEYWORDS: Enterococcus faecalis, sodium hypochlorite and ozonated oil.

\section{INTRODUCTION}

Removal of bacteria, debris and necrotic tissue is necessary for the success of root canal therapy in primary teeth. However, to completely eliminate bacteria and necrotic debris mechanical preparation and adjunctive use of root canal irrigants are needed
(Ramachandra et al. 2015). Intracanal irrigants work along with mechanical debridement by flushing out debris, dissolving tissue and disinfecting the root canal system (Ismail et al. 2017).

In infected root canals, the bacterial strain most commonly isolated is Enterococcus faecalis,

\footnotetext{
* Lecturer of Pediatric Dentistry and Dental Public Health, Faculty of Dentistry - Cairo University.
} 
also considered the most persistent bacteria in root canals. Enterococcus faecalis is a Grampositive facultative anaerobe which penetrates dentinal tubules and can attach to the dentin. In addition, the bacterial strains are highly resistant to many irrigating solutions and medications used in endodontics. Therefore, Enterococcus faecalis can survive for a long time in the root canals (Hubbezoglu et al. 2014).

Sodium hypochlorite $(\mathrm{NaOCl})$ is the most commonly used irrigating solution. It acts on microbial cells disrupting the vital functions of the cell leading to the cell death. (Ramachandra et al. 2015). However, $\mathrm{NaOCl}$ has an unpleasant taste and odor, which may be a source of discomfort and irritation for children with increased risk if remnants are swallowed. In addition, $\mathrm{NaOCl}$ removes the smear layer only partially, does not consistently disinfect the root canal and is toxic to the periradicular tissues (Ismail et al. 2017).

New generations of disinfecting agents have been developed among them is ozone, which is a powerful oxidizing agent and can be used to eliminate bacteria in root canals (Hubbezoglu et al. 2014).

Ozone $\left(\mathrm{O}_{3}\right)$ is a molecule of three oxygen atoms. Oxygen molecule $\left(\mathrm{O}_{2}\right)$ when subjected to photo dissociation results in activated oxygen atoms. An active oxygen atom combines with an oxygen molecule resulting in ozone molecule formation $\left(\mathrm{O}_{3}\right)$. On combination with a proton, hydrogen trioxide $\left(\mathrm{HO}_{3}\right)$ is formed which decomposes to a more powerful oxidant, the hydroxyl radical $(\mathrm{OH})$. Clinically, ozone generator is used to simulate the natural reaction via an electrical discharge field (Saini 2011). The bactericidal effect of ozone is due to the formation of oxidated radicals in aqueous solutions, this will cause changes in the osmotic permaeability of the cell membranes resulting in cell damage (Üreyen Kaya et al. 2014).

There is an increasing interest in the use of ozone in dentistry as it has a high oxidizing potential, antimicrobial effect, debriding action, stimulates blood circulation and angiogenesis, analgesic and anti-inflammatory effect and enhancing the immune response. Recently, studies are considering its use as alternative antiseptic agent in the field of dentistry because of its antibacterial properties without the risk of drug resistance developement (Saini 2011, Chandra et al. 2014 and Srinivasan \& Chitra 2015).

Ozone is used in many disciplines of dentistry as periodontology, endodontics, surgery, pediatric dentistry, and conservative dentistry. The actions of ozone include the elimination of bacterial pathogens, periodontal pockets disinfection, prevention of caries, tooth sensitivity, accelerate healing, tissue regeneration, remineralization of tooth surface, before fissure sealant placement, in cases with apthous ulcers and herpetic lesions, and disinfecting dental waterline. (Saini 2011, Khullar et al. 2012 and Eregowda \& Poornima 2016)

There are different forms for application of ozone as ozone gas, ozonated water, and ozonated oil that are used for canals irrigation and as intra canal medications to obtain disinfection of root canal systems. Ozonated water and olive oil act by entrapping ozone then releasing it. (Kishore et al. 2016)

Ozonated oils are obtained by means of chemical reactions that pass pure oxygen and ozone through the oils. The product is a viscous oil containing ozonides (Pattanaik et al. 2011). Ozonated oils can also be used as intracanal medications because of its viscosity (Kishore et al. 2016).

Use of ozonated oil in dentistry is an area of research and few studies have been found addressing its use as intracanal irrigant or medicament, therefore the aim of this study is to investigate the antimicrobial activity of ozonated olive oil versus sodium hypochlorite against Enterococcus faecalis. 


\section{METHODOLOGY}

The present in-vitro study was conducted to compare the antibacterial inhibitory effect of ozonated olive oil and sodium hypochlorite solution (test and control group respectively) on Enterococcus faecalis using agar well diffusion test.

\section{Ethical approval}

Ethical approval was obtained from the Research Ethics Committee (REC), Faculty of Dentistry, Cairo University with ethical approval number 19939

\section{Sample size estimation:}

Sample size of 36 samples (18 for each group) was estimated using GPower 3.1.9.4 program according to the results of Savitri et al., 2018 (with $\alpha$ set at $0.05 \&$ power set at 0.8 ).

\section{Test materials}

i- Sodium hypochlorite: $1 \%$ sodium hypochlorite solution (Clorox, Egypt). (American Academy of Pediatric Dentistry, 2017)

ii- Ozonated oil: Ozonated olive oil was obtained by using Dr. Hansler ozonosan ${ }^{\circledR}$ ozone generator (Iffezheim, Germany).

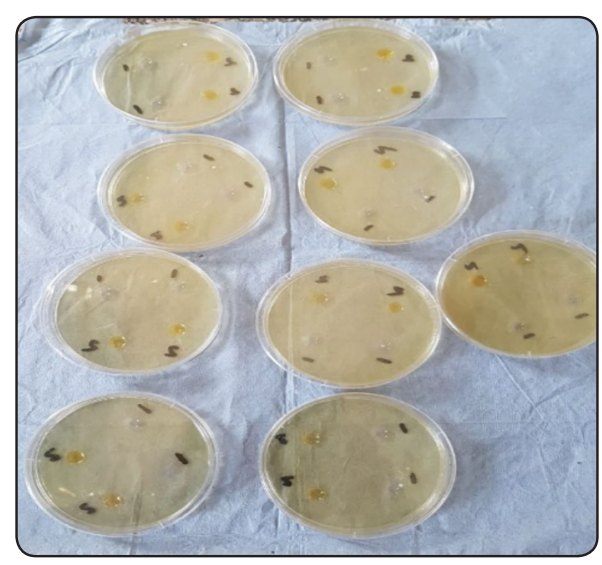

Fig. (1) Agar plates inoculated with bacteria and test materials placed in the wells.

\section{Test microorganisms}

Bile esculin agar selective media was used to selectively isolate and identify strains of Enterococcus faecalis obtained from the Department of Microbiology, Faculty of Medicine, Cairo University. Freeze-dried reference microorganisms, Enterococcus faecalis ATCC 29212 were used.

\section{Agar well-diffusion test and inoculation of agar plates}

The cultures were inoculated into sterile brain heart infusion (BHI) broth and incubated at $37^{\circ} \mathrm{C}$ and the turbidity of 0.5 Mcfarland standard was achieved.

Sterile cotton swabs were dipped in the broth and streaked on the Brain Heart agar media plates. Sterile template was used to cut four wells $(5 \mathrm{~mm}$ in diameter) at equal distances in each agar plate. In each plate, $50 \mu \mathrm{l}$ of $1 \%$ sodium hypochlorite solution (group 1) were put in two wells and 50 $\mu \mathrm{l}$ of ozonated olive oil (group 2) were placed in the other two wells using sterile micro pippettes. The plates were then incubated at $37^{\circ} \mathrm{C}$ for $24 \mathrm{~h}$. (Figure 1)

Zones of bacterial growth inhibition around the wells containing the test materials were measured and recorded after $24 \mathrm{~h}$ and $48 \mathrm{~h}$ of incubation.

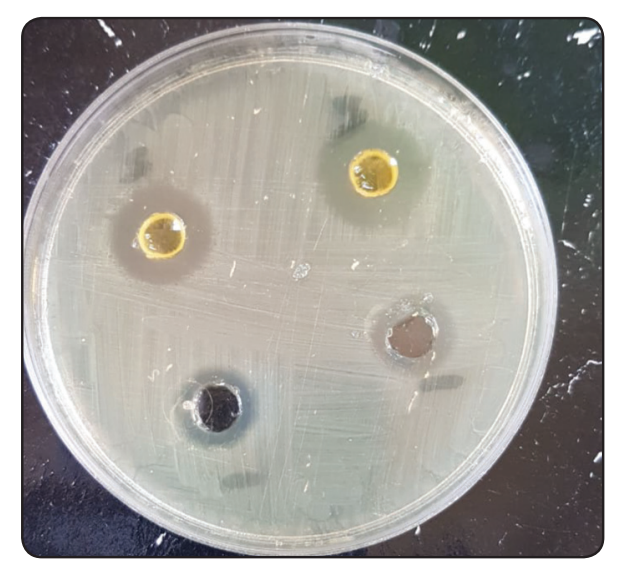

Fig. (2) Zones of bacterial growth inhibition around the test materials. 
The diameter of the zone of inhibition of bacterial growth around the well was measured using ruler (in $\mathrm{mm}$ ). (Figure 2)

\section{RESULTS}

Statistical analysis was performed using SPSS software program (SPSS 18; SPSS, Chicago, IL, USA). Data were presented as mean \pm standard deviation (mean $\pm \mathrm{SD}$ ). Diameters of the zones of bacteraial growth inhibition (in $\mathrm{mm}$ ) were compared between both groups using independent $t$ test. The level of significance was set at $\boldsymbol{p}<0.05$.

The mean values for the diameter of zones of bacterial inhibition for both groups after $24 \mathrm{~h}$ are shown in (Table 1).

TABLE (1) The mean values for the diameter of zones of bacterial inhibition for both groups after $24 \mathrm{~h}$.

\begin{tabular}{|c|c|c|}
\hline Groups & $\begin{array}{c}\text { Mean diameter of } \\
\text { inhibition zone }(\mathbf{m m})\end{array}$ & $\begin{array}{c}\text { Standard } \\
\text { deviation }\end{array}$ \\
\hline Group (1) & 13.28 & \pm 1.127 \\
\hline Group (2) & 21.22 & \pm 1.396 \\
\hline $\begin{array}{c}\text { p- value } \\
\text { (between groups) }\end{array}$ & $0.00^{*}$ & \\
\hline
\end{tabular}

Significance level $p<0.05$, *significant

There was no change in the diameter of the inhibition zones after 48 hours.

\section{DISCUSSION}

Root canal treatment in primary teeth is a challenge because of the morphology of the primary molar roots and root canals, the physiologic root resorption that occurs, and the operators' care to avoid any possible damage for the permanent successors. Mechanical cleaning and instrumentation and adequate disinfection of the canals are prerequisites for successful root canal therapy (Pozos-Guillen et al.2016). An ideal irrigant would allow disinfection, flush away debris, help to provide lubrication for the files while avoiding any irritation to the periapical tissues (Chaugule et al. 2015).

In the present study the antimicrobial activity of ozonated olive oil in comparison to sodium hypochlorite against Enterococcus faecalis bacteria have been investigated. Sodium hypochlorite $(\mathrm{NaOCl})$ is commonly used as an irrigant, however, it has a disagreeable taste in addition to its risk of causing cytotoxic response for periapical tissues or oral mucosa (Prebeg et al. 2016). Ozone was selected in this study as it is a potent antibacterial agent with low cytotoxicity and so can be safe when used in endodontic treatment (Nogales et al. 2016).

In the present study, ozone oil was opted for since ozone is unstable in gaseous form and requires special devices to be present chairside, also ozonated water has short shelf life as it rapidly decomposes. Ozonated oils due to their oily consistency can remain in contact with the tissues for longer a time extending their time of action. Also the prepared oils have a longer shelf life (that can be months) compared to ozonated water (Chandra et al. 2014 and Pratyusha \& Selvan 2017).

Enterococcus faecalis was chosen as the test micro-organism as it is one of the most frequently isolated in teeth with pulp necrosis (lacking previous history of endodontic treatment) and also in teeth with recurrent infection (Rodríguez-Niklitschek \& Oporto V 2015).

Agar well diffusion test was used to test the antibacterial properties of the test materials as it is commonly used to determine the antibacterial effect of dental materials and it is one of the most common and simple methods.(Pietrocola et al. 2018)

The results of the present study showed higher antibacterial effect of ozonated olive oil when compared to sodium hypochlorite solution. The values of the diameters of the bacterial inhibition zones did not change after $48 \mathrm{~h}$. 
These results are in accordance with (Pratyusha \& Selvan 2017) who compared the antibacterial efficacy of ozonated olive oil, cold pressed neem oil, $2 \%$ chlorohexidine and calcium hydroxide against Enterococcus faecalis. The results of their study showed maximum inhibitory effect against Enterococcus faecalis by ozonated olive oil. Also (Kishore et al. 2016) investigated the antimicrobial efficacy of calcium hydroxide, ozonated sesame oil and their combination as intra canal medicament, they concluded that ozonized sesame oil was most effective for longer duration when compared to other groups.

On the other hand, in studies comparing ozonated water with other antibacterial agents, the results showed lower antibacterial effect of ozonated water.

(Wali et al. 2008) stated that ozonated water showed less antimicrobial effect against Enterococcus faecalis and Candida albicans compared to chlorohexidine and sodium hypochlorite. (Savitri et al. 2018) also reported lower antibacterial effect of ozonated water against Enterococcus faecalis compared to chlorohexidine and sodium hypochlorite.

Therefore, ozonated olive oil has the advantage of being used as intracanal mediaction and can also be used as intracanal irrigant. Ozonated oils have long shelf life and can easily be purchased without the need for expensive chairside equipments.

In spite of its many advantages, there are certain contraindications for the use of ozone including pregnancy, hyperthyroidism, hemorrhage, favism, severe anemia, thrombocytopenia, and ozone allergy (Mohammadi et al. 2013 and Eregowda \& Poornima 2016).

Further clinical studies are recommended where ozonated olive oil can be used as intracanal medication or irrigant. Also further studies to test the ozonated oil as a root canal filling material in combination with zinc-oxide powder, testing its resorbability and effect on the shedding process of primary teeth.

\section{CONCLUSIONS}

The present study showed that antibacterial effect of ozonated oil is superior to that of sodium hypochlorite.

\section{REFERENCES}

1. American Academy of Pediatric Dentistry, 2017. Pulp therapy for primary and immature permanent teeth. Pediatric Dentistry, 39(6), pp.325-333.

2. Chandra, S.P. et al., 2014. Success of root fillings with zinc oxide-ozonated oil in primary molars: preliminary results. European Archives of Paediatric Dentistry, 15(3), pp.191195. Available at: http://link.springer.com/10.1007/ s40368-013-0094-8.

3. Chaugule, V.B., Panse,A.M.\& Gawali, P.N., 2015.Adverse Reaction of Sodium Hypochlorite during Endodontic Treatment of Primary Teeth. International journal of clinical pediatric dentistry, 8(2), pp.153-6. Available at: http://www.ncbi.nlm.nih.gov/pubmed/26379387.

4. Eregowda, N.I. \& Poornima, P., 2016. Ozone in Dentistry I on WordPress.com. Indian Journal of Dental Advancements, 07(JUNE 2015). Available at: http://blog. deltadental.com/2013/07/17/ozone-in-dentistry/.

5. Hubbezoglu, I. et al., 2014. Antibacterial Efficacy of Aqueous Ozone in Root Canals Infected by Enterococcus faecalis. Jundishapur journal of microbiology, 7(7), p.e11411. Available at: http://www.ncbi.nlm.nih.gov/ pubmed/25368798.

6. Ismail, S., Adyanthaya, A. \& Sreelakshmi, N., 2017. Intracanal irrigants in pediatric endodontics: A review. International Journal of Applied Dental Sciences, 3(4), pp.246-251.

7. Khullar, S. et al., 2012. Ozone Therapy In Pediatric Dentistry: An Alternate Approach. The Internet Journal of Dental Science, 10(2), pp.1-7.

8. Kishore, A., Obulesu, G. \& Babu, M., 2016. Determination of Antimicrobial Efficacy of Calcium hydroxide, Ozonated sesame oil and their combination as intra canal medicament against Enterococcus faecalis - A Study in Fathima Institute of Medical Sciences, Kadapa. International Archives of Integrated Medicine, 3(8), pp.219-227. Available at: http://search.ebscohost.com/login.aspx ?direct=true $\& d b=a$ 9h\&AN=117591439\&site=ehost-live. 
9. Mohammadi, Z. et al., 2013. A review of the properties and applications of ozone in endodontics: an update. Iranian endodontic journal, 8(2), pp.40-3. Available at: http:// www.ncbi.nlm.nih.gov/pubmed/23717326.

10. Nogales, C.G. et al., 2016. Ozone therapy as an adjuvant for endondontic protocols: microbiological - ex vivo study and citotoxicity analyses. Journal of Applied Oral Science, 24(6), pp.607-613. Available at: http://www. scielo.br/scielo.php?script=sci_arttext $\&$ pid $=$ S 1678 $77572016000600607 \& \operatorname{lng}=$ en\&tlng=en.

11. Pattanaik, B. et al., 2011. Ozone therapy in dentistry: A literature review. Journal of Interdisciplinary Dentistry, 1(2), p.87. Available at: http://www.jidonline.com/text. asp?2011/1/2/87/85024.

12. Pietrocola, G. et al., 2018. Evaluation of the antibacterial activity of a new ozonized olive oil against oral and periodontal pathogens. Journal of clinical and experimental dentistry, 10(11), pp.e1103-e1108. Available at: http:// www.ncbi.nlm.nih.gov/pubmed/30607228.

13. Pozos-Guillen, A. et al., 2016. Intracanal irrigants for pulpectomy in primary teeth: a systematic review and meta-analysis. International Journal of Paediatric Dentistry, 26(6), pp.412-425. Available at: http://doi. wiley.com/10.1111/ipd.12228.

14. Pratyusha, M. V \& Selvan, A., 2017. Evaluation of Antibacterial Efficacy of Ozonated Olive Oil and Cold Pressed Neem Oil Against Enterococcus. Available at: http://www.journalcra.com.

15. Prebeg, D. et al., 2016. Antimicrobial Effect of Ozone Made by KP Syringe of High-Frequency Ozone Generator. Acta stomatologica Croatica, 50(2), pp.134-142. Available at: http://www.ncbi.nlm.nih.gov/pubmed/27789911.

16. Ramachandra, J.A. et al., 2015. Root canal irrigants in primary teeth. World Journal of Dentistry, 6(4), pp.229-234.
17. Rodríguez-Niklitschek, C. \& Oporto V, G.H., 2015. Clinical implications of Enterococcus faecalis microbial contamination in root canals of devitalized teeth: Literature review. Revista Odontológica Mexicana, 19(3), pp.e177-e182. Available at: https://www.sciencedirect. com/science/article/pii/S1870199X16000422.

18. Saini, R., 2011. Ozone therapy in dentistry: A strategic review. Journal of natural science, biology, and medicine, 2(2), pp.151-3. Available at: http://www.ncbi.nlm.nih.gov/ pubmed/22346227.

19. Savitri, D. et al., 2018. Efficacy of ozonated water, 2\% chlorhexidine and $5.25 \%$ sodium hypochlorite on five microorganisms of endodontic infection: In vitro study. Advances in Human Biology, 8(1), p.19. Available at: http://www.aihbonline.com/text.asp?2018/8/1/19/222246.

20. Silveira, A.M.V. et al., 2007. Periradicular repair after twovisit endodontic treatment using two different intracanal medications compared to single-visit endodontic treatment. Brazilian Dental Journal, 18(4), pp.299-304.

21. Srinivasan, K. \& Chitra, S., 2015. The Application of Ozone in Dentistry: A Systematic Review of Literature. Scholars Journal of Dental Sciences, 2(6), pp.373-377.

22. Üreyen Kaya, B. et al., 2014. Efficacy of endodontic applications of ozone and low-temperature atmospheric pressure plasma on root canals infected with Enterococcus faecalis. Letters in Applied Microbiology, 58(1), pp.8-15. Available at: http://doi.wiley.com/10.1111/lam.12148.

23. Wali, I.E. et al., 2008. The Antimicrobial Efficacy of Ozonated Water, Chlorhexidine and Sodium Hypochlorite against Single Species Biofilms of Enterococcus faecalis and Candida albicans. Egyptian Journal of Medical Microbiology, 17(3), pp.419-428. 